\title{
Progressive trends in timing and imaging of lower extremity reconstruction
}

\author{
Andrew Y. Zhang ${ }^{1, \#, ~ D a v i d ~ C h o l o k ~}{ }^{2, \#, ~ G o r d o n ~ K . ~ L e e ~}{ }^{2}$ \\ 'Department of Plastic Surgery, University of Texas Southwestern Medical Center, Dallas, TX, USA. \\ 2Division of Plastic and Reconstructive Surgery, Stanford University, Palo Alto, CA, USA. \\ \#Authors contributed equally.
}

Correspondence to: Dr. Gordon K. Lee, Division of Plastic and Reconstructive Surgery, Stanford University, 770 Welch Road, Suite 400, Stanford, CA 94304, USA. E-mail: glee@stanford.edu

\begin{abstract}
How to cite this article: Zhang AY, Cholok D, Lee GK. Progressive trends in timing and imaging of lower extremity reconstruction. Plast Aesthet Res 2019;6:30. http://dx.doi.org/10.20517/2347-9264.2019.040
\end{abstract}

Received: 15 Oct 2019 First Decision: 15 Nov 2019 Revised: 19 Nov 2019 Accepted: 9 Dec 2019 Published: 17 Dec 2019

Science Editor: Matthew L. Iorio Copy Editor: Jing-Wen Zhang Production Editor: Jing Yu

\begin{abstract}
The salvage of mangled lower-extremities after severe injury remains a daunting operative dilemma, but one that continues to evolve with advances in microsurgical and orthopedic techniques. Specifically, trends in clinical practice including the decision to salvage and timing of soft-tissue coverage are changing in concordance with improvements in wound care, flap selection for soft-tissue provision, and preoperative imaging. Due to these improvements, more complex wounds are increasingly eligible for reconstruction. It remains unclear, however, whether success in limb salvage confers improved functional patient outcomes. We present a review of the literature tracing recent advances in the salvage of mangled extremities following traumatic injury, with a focus on practice trends regarding timing of reconstruction, operative approaches, and preoperative imaging.
\end{abstract}

Keywords: Lower extremity, reconstruction, propeller flaps, amputation, microsurgery, trauma

\section{INTRODUCTION}

Complex high-energy trauma to the lower extremity often entails significant and devastating morbidity for patients. Lower extremity injury accounts for greater than 250,000 hospital admissions each year in the US; more than half involve open long-bone fractures, crush, or major soft-tissue injury ${ }^{[1]}$. Return of function can be an arduous process requiring multidisciplinary care and ongoing therapy for months to years. Plastic surgeons involved in the care of these patients should be well versed in the unique demands required

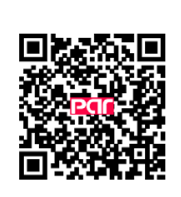


by reconstruction of these complex anatomic and functional deficits. Clinical decision-making should be guided by our developing understanding of tissue physiology, orthopedic reconstructive principles, and developing technology used to guide preoperative planning and intraoperative decision making. When effective, limb reconstruction can confer a close approximation of pre-morbid functionality. However, the calculus of when, how, and on whom to intervene remains incompletely defined and often plagued by equivocation. Fortunately, the tools used to assess the severity and distribution of injury, including expanding use of novel imaging techniques, as well as refinement of reconstructive approaches continue to develop. This review focuses on the advances made regarding approaches in surgical management and perioperative assessment of complex lower-extremity injuries. Advances in orthopedic fixation, as well as advances in the provision of soft-tissue reconstruction, guided by long-standing principles of surgical management continue to drive the functional, aesthetic, and patient-centered outcomes conferred by limbsalvage.

\section{INITIAL ASSESSMENT AND DECISION TO PROCEED WITH LIMB SALVAGE}

The inclination to salvage a mangled extremity, by any means necessary, is an understandable reflex for patients and physicians alike. This inclination, however, belies the utility of amputation in restoring functionality of patients. Data from the landmark, Lower Extremity Assessment Project (LEAP) group, published in 2002, provide the most thorough analysis to date of lower extremity trauma treatment and outcomes, including demographic data of the civilian population who suffer these injuries as well as their ultimate functional status and variables surrounding their recovery ${ }^{[2]}$. The study found comparable functional outcomes among individuals who had undergone reconstruction versus those who had undergone amputation. Roughly one half of all patients followed for the duration of the study exhibited significant disability as objectively assessed by the Sickness Impact Profile score. The sobering conclusion gleaned from this multi-center study was that reconstruction conferred no functional benefit when compared with amputation, and outcomes from both groups were poor; little more than $30 \%$ of patients exhibited return to functionality compared with uninjured age-matched counterparts, and fewer than $60 \%$ of patients had returned to work at seven years post-injury. These conclusions, however, should be weighed critically, as subsequent analyses highlight the impact of socioeconomic factors, as opposed to treatment course, as predictors of ultimate outcomes ${ }^{[3,4]}$. It should be emphasized that the LEAP trial focused on civilian patients. Much of the literature regarding advances in lower extremity reconstruction following high-energy trauma has been gleaned from the arena of combat. As such, treatment guidelines taken from one patient population, while informing of the other, cannot be translated without qualification, given distinct mechanisms of injury, concurrent trauma/injury, treatment setting, etc. ${ }^{[5]}$. Despite the multitude of wound assessment and grading scales (discussed in more detail below), there remain no hard and fast rules regarding when a severely damaged limb should be amputated [Figure 1]. Despite previous orthodoxy, damage to posterior tibial nerve, and an insensate foot are no longer absolute contra-indications for limb salvage ${ }^{[6,7]}$. Instead, reconstruction should be evaluated and approached on a case by case basis and must be in line with the ultimate goals of the patient.

\section{ASSESSMENT OF INJURY AND PROGNOSIS OF RECONSTRUCTION}

Multiple validated grading scales exist for the purposes of assessing extremities following traumatic injury and attempt to guide treatment accordingly. Unfortunately, all have demonstrated limited utility when applied in the clinical setting, and there remains no gold standard of a translatable universally applicable injury assessment tool. Nevertheless, the injury assessment scales, including the Mangled Extremity Severity Score ${ }^{[7]}$, Predictive Salvage Index ${ }^{[8]}$, Limb Salvage Index ${ }^{[\rho]}$, and the Nerve Injury, Ischemia, Soft Tissue Injury, Skeletal Injury, Shock, and Age of the Patient ${ }^{[10]}$ score, provide an objective and structured assessment of complex injuries. Each purportedly identifies unique variables predictive of ultimate amputation, including level of arterial injury, timing from injury to index operation, volume of soft tissue 

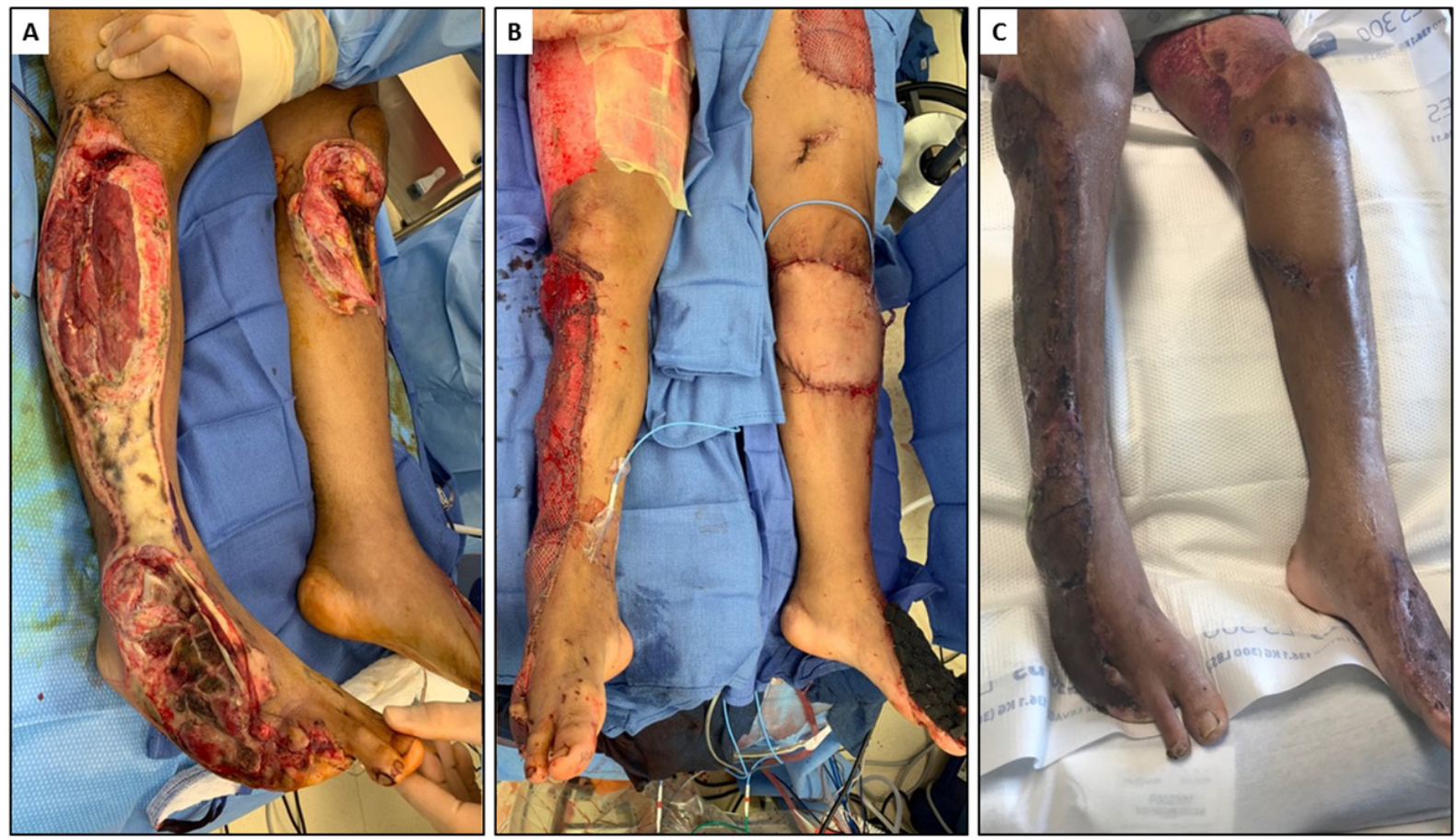

Figure 1. A: adult male struck by motor vehicle. Resulting degloving injuries included exposure of right femoral head, visible peroneal nerve, exposure of right metatarsals, and exposure of left proximal tibia; B: immediate reconstruction with lateral gastrocnemius pedicled flap with STSG to proximal right leg, free rectus abdominus flap with STSG to dorsal right foot, and free anterolateral thigh flap to proximal left leg. Dorsal left foot covered with integra, and subsequently skin grafted; C: patient six weeks after initial reconstruction. STSG: split thickness skin graft

lost, etc., which are ostensibly essential in the characterization of the injury. However, using a dataset of over 500 patients with lower extremity trauma, Bosse et al ${ }^{[11]}$ prospectively analyzed seven commonly used injury severity scales and found these scales to have limited utility in predicting amputation versus salvage. Each of these scales demonstrated adequate sensitivity, but limited specificity, in which low scores were concordant with salvage potential, but increasing values provided no indication regarding the likelihood of amputation in injuries thought to be more severe. This work serves to cement the salience of individualized assessment and care tailored to the unique circumstances of the patient.

The Gustilo-Anderson classification of open fractures remains a relevant and commonly used assessment tool, to grade open fractures in the setting of lower extremity injury. The classification system, and subsequent modification subdivide severity of injury into three categories, each with ascending level with increasing involvement of soft-tissue, and ultimate vascular injury ${ }^{[12,13]}$. This classification system, however, was devised to assess risk of subsequent infection and does not aim to predict likelihood of amputation. Nonetheless, the Gustilo classification is an effective scale with demonstrated intra-observer reproducibility ${ }^{[14]}$.

The determinants of a patient's prognosis following reconstruction are multiple, varied, and not solely dependent on the wound itself, timing of reconstructions, or approach to treatment; as observed in the LEAP trial, most independent risk factors for poor functional outcomes and amputation include socioeconomic circumstance of the patient's and not the treatment plan initially employed ${ }^{[3]}$. Again, the decision to proceed with reconstruction versus amputation is dependent on the gestalt of the patient and injury. Patients must not only overcome modifiable risk factors, and pathophysiologic sequelae of systemic disease; public perception and stigma regarding amputation continue to complicate the personal decision of whether to proceed with amputation, as well as the support network of the patient during their recovery ${ }^{[15]}$. 


\section{TIMING OF RECONSTRUCTION}

Historically, surgeons have advocated for prompt soft-tissue coverage of lower-extremity defects following trauma ${ }^{[16,17]}$. In his landmark study in 1986 , Godina demonstrated improved rates of flap loss, infection, and length of hospital stay with soft-tissue coverage provided within the first $72-\mathrm{h}$ of injury ${ }^{[16]}$. Three days remains the benchmark goal for acute reconstruction. Indeed, despite a trend towards a more permissive timeline of soft-tissue coverage, recent analyses corroborate improved free-flap failure rates and reduced rates of infection with immediate reconstruction within the 72 -h window, although these statistical analyses remain dependent on Godina's index cohort of over 500 patients, to date the most prolific of studies analyzed ${ }^{[18]}$. Obviously, surgeons strive for prompt bony stabilization and soft-tissue coverage as soon as logistically possible; however, clinical reality and the presence of concomitant injury to vital organ systems often preclude definitive reconstruction in the acute setting. Facilitated by advances in wound care, this critical window has since been liberalized in the setting of recent studies demonstrating noninferior outcomes with reconstruction in the subacute and chronic phases of injury following serial debridement without compromise of flap survival rates or patient function ${ }^{[17,19-25]}$. This trend has accelerated over the previous decade: the mean timing of definitive reconstruction has progressed from 6 to 12.5 days in the decade from 2002 to $2011^{[26]}$. This trend also reflects the prioritization of adequate wound debridement to ensure adequate preparation of the recipient wound bed. As demonstrated by Karanas et al. ${ }^{[20]}$, definitive soft-tissue coverage should allow for serial debridement to minimize the risk of catastrophic deep-space, or bony infection, even if this process delays reconstruction outside of the acute window. Data from the armed combat literature also underlie the importance of ensuring a clean and adequately debrided wound bed ${ }^{[27]}$. Pollak et al. ${ }^{[27]}$ found that time to initial operative debridement was not an independent risk factor for the risk of infection following high-energy low-extremity trauma; however, prompt admission to definitive trauma treatment center was protective, suggesting prompt global patient management and wound care is essential to favorable reconstructive outcomes.

Perhaps more than any other therapeutic advancement, the widespread use of negative pressure wound therapy (NPWT) has proven essential for the temporization of definitive reconstruction ${ }^{[2,24,28]}$. Multiple hypotheses exist as to why the physiologic advantages of NPWT have facilitated the optimization of wound care including providing ideal wound healing environment via minimization of edema, reducing surface area of the wound, and providing reduced capillary afterload translating to increased perfusion of nascent granulation tissue ${ }^{[29,30]}$. Indeed, the physiological benefits attributed to NPWT are felt to oppose the effects of tissue fibrosis, inflammation, and edema thought to potentially threaten microvascular anastomoses driving the emphasis of early reconstruction. The use of NPWT has extended the critical time to definitive soft-tissue coverage to as far out as weeks to months from the initial injury, with numerous studies documenting comparable rates of flap loss, infection, and hospital stay following soft tissue coverage. In fact, certain cohorts report improved outcomes approaching significance of chronically reconstructed wounds compared with more acute reconstruction, lending further credence to temporization of reconstruction outside of the acute window ${ }^{[24]}$. As initially observed by Steiert et $a l^{[22]}$, increasingly permissive time to definitive coverage appears concordant with the increasing complexity of the wounds being reconstructed, which helps to better understand the deviation from the 72-h orthodoxy. To be clear, when feasible, recent data still corroborate improved outcomes with earlier reconstruction. The work of Liu et al ${ }^{[23]}$ demonstrated that, while delay to definitive reconstruction past seven days conferred increased risk for osteomyelitis and potential flap complications, NPWT was protective against reoperation and venous thrombosis in those populations unable to undergo acute reconstruction. Taken together, prompt reconstruction should remain the operative goal, but timing should involve nuanced considerations of the patient and injury, as excellent outcomes remain feasible long after the previously espoused $72-\mathrm{h}$ window ${ }^{[31]}$. Unfortunately, operative considerations are not the only determinants of timing to reconstruction; the work of Shammas et al. ${ }^{[32]}$ identified a number of sociodemographic risk factors, including older age, nonwhite race, and geographic region for delays to soft tissue coverage. Acute reconstruction should not 
be performed at the expense of patient and wound optimization, as definitive soft-tissue coverage in the subacute, and chronic intervals have been demonstrated to be safe and effective.

Soft tissue coverage is similarly dependent on the integrity of bony fixation to provide adequate tension across joints for preservation of locomotion, and to prevent collapse of soft-tissues. Fortunately, the science and practice of orthopedic reduction and fixation has developed in parallel with microsurgical techniques. Amongst the most challenging operative dilemmas from orthopedic injury is the management of resulting segmental defects. Multiple surgical strategies exist and remain used in clinical practice to restore bony length and adequate union following traumatic bone loss or defects resulting from debridement. Techniques including distraction osteogenesis (Ilizarov Technique), autologous bone grafting, and mesh implants have demonstrated adequate results regarding ultimate restoration of bone length and stability $^{[33-35]}$. More recently, the Masquelet technique has emerged as a novel and reliable strategy for the purposes of restoration of bone defects ${ }^{[36]}$. Initially described in results published in 2000, the strategy utilizes staged operations to induce a periosteum surrogate, "Inflammatory Membrane", around a cement spacer, which is subsequently replaced with autologous bone $\operatorname{graft}^{[37,38]}$. Amongst multiple retrospective studies, clinical success rates have been reported in up to $89 \%-93 \%$ of cases, despite bony defects greater than $10 \mathrm{~cm}^{[39,40]}$. Despite the paucity of long-term functional outcomes, the technique has gained clinical traction, and has been used increasingly in concert with advances in provision of soft-tissue coverage for the purposes of lower extremity reconstruction.

\section{OPERATIVE CONSIDERATIONS OF RECONSTRUCTION}

Once the degree of injury has been appropriately assessed, the decision to proceed with reconstruction has been made, and the stability of the wound bed has been assured, considerations regarding the appropriate tissue to be transplanted must be made. General principles regarding the distribution of injury and corresponding donor site of soft-tissue coverage remain applicable and continue to guide surgical management. The tenets of the reconstructive ladder remain applicable when reconstructing lower extremity injuries. Often, despite significant fractures, local muscle flap coverage and skin grafting provide excellent results. However, given unique challenges posed at certain areas, namely around the knee and proximal tibia, as well as the distal leg, ankle, and foot, surgeons are increasingly utilizing more complex solutions, as espoused by the "reconstructive elevator" paradigm. As conceived and popularized by Gottlieb and Krieger ${ }^{[41]}$, the reconstructive elevator argues for skipping over simpler solutions in favor of a reconstructive approach that more accurately approximates the functional and anatomic deficits of the injury. For instance, given the paucity of tissue, and resulting exposure of bony and articulating surfaces, free-flap reconstruction has become the default surgical option for injuries of the distal lower extremity.

While certain micro-surgical principles have remained unchallenged, recent data have led to the liberalization of other reconstructive dogmas held by many practicing surgeons. The requirement of a clean wound bed for recipient tissue remains an immutable tenet of reconstruction. The translation of autologous tissue should only occur in a clean wound-bed free of necrotic or infected tissue, and preferably over appropriately reduced bony framework. In contrast, discussion regarding the selection of autologous tissue to be harvested as well as the selection of recipient vasculature continues to evolve. Recently, a trend towards the use of perforator fasciocutaneous flaps has proportionately displaced the use of bulkier myofasciocutaneous free-flaps ${ }^{[42]}$. Improved understanding of perfasomes, and increasing facility with perforator dissection have resulted in the wide-spread adoption of using fasciocutaneous flaps for extremity reconstruction ${ }^{[42,43]}$. Despite concerns that the use of fasciocutaneous flaps preclude the superior blood supply conferred by transferred muscle, these flaps are no more prone to ischemia and flap failure. Similarly, fasciocutaneous flaps are resistant to shear and breakdown in weight bearing areas when compared with muscle containing flaps ${ }^{[44]}$. That being said, multiple "work-horse" flaps provide appropriate 
tissue qualities for corresponding defects: the latissimus dorsi flap provides significant tissue bulk for large tissue deficits, the neurotized gracilis flap provides potential for restoration of active motion, etc. In a span of 30 years, microsurgical flaps have become common practice in lower extremity reconstruction. There remains a disproportionately high rate of complications of free-flaps in microsurgical reconstruction, with a $14 \%$ rate of major complications cited in a retrospective review of over 400 injuries. Independent risk factors for flap compromise include prolonged operative time, preoperative anemia, steroid use, and diabetes $^{[45]}$.

Other considerations, including selection of recipient vessels, remain of paramount importance. Clinical orthodoxy favors selection of vessels proximal to the site of injury, given progressive decrease in size of available source vessels more distal in the leg. However, this orthodoxy has recently been challenged by select institutions, as selection of recipient vessels distal to the site of injury was recently demonstrated to be non-inferior in a retrospective review of 312 free-tissue transfers for soft-tissue reconstructions of open tibial fractures ${ }^{[46]}$. This remains a point of contention, but feasibility provides an alternative in the event of complication precluding more proximal access.

A common paradigm in the reconstruction of lower extremity remains the anatomic subdivision of the leg into thirds: proximal, middle, and distal. The distal third provides unique reconstructive challenges due to paucity of local tissue available for local tissue rearrangement, and superficial distribution of structures requiring coverage. As such, the distal third of the leg manifests the opportunity to put the principles of the "reconstructive elevator", into practice, yet remains plagued by higher rates of complications ${ }^{[47]}$. Free-flaps remain the preferred option for reconstruction of substantial deficits in this region. However, comparison of free-flap coverage demonstrates increase rates of free-flap loss, and complications at the distal third of lower extremity injuries, when compared to more proximal leg injuries ${ }^{[47,48]}$. The use of propeller flaps has arisen as a viable option for soft-tissue coverage when free-tissue transfer is contraindicated, or simply not feasible ${ }^{[49]}$ [Figure 2]. Propeller flaps provide substantial soft-tissue for coverage of essential structures via improved understanding of perfosome distribution without need for microanastomosis in precarious anatomic regions. Historically, perforator flaps had been thought to require thick cuffs of subcutaneous tissue to protect the pedicle from kinking, thereby restricting the arc of rotation, and often resulted in dog-ears at the axis of rotation. As understanding of perfasomes has advanced, including the course and distribution of these short branching vessels, local pedicled flaps have been used with increasing regularity for lower extremity reconstruction ${ }^{[4,50]}$. Particularly in the distal third of the lower extremity, multiple local flaps including the reverse sural fasciocutaneous flaps can be used with regularity to reconstruct complex defects, and can be staged as delayed flaps without any question of tissue viability ${ }^{[51,52]}$. More proximally, muscle flaps, such as the anterior tibial and soleus flaps, can be translated to cover bony defects following trauma, further establishing the role of local pedicled flaps in soft-tissue reconstruction of the lower extremity.

\section{ADVANCES REGARDING IMAGING TECHNOLOGY TO ASSESS LOWER EXTREMITY INJURY}

Imaging in the setting of complex injury can be used to not only evaluate the viability of limb salvage, but also to orient eventual reconstruction via the identification, localization, and qualitative assessment of potential recipient vessels for purposes of microvascular reconstruction. Hard signs of ischemia, including hemorrhage, expanding hematoma, and absent distal pulses, are sufficient to prompt operative intervention to ensure continued perfusion of the distal extremity; in the absence of obvious signs, however, modalities used for assessment of vascular injury remain variable and institution dependent.

The "gold standard" of evaluating vascular injury remains arteriography, but this modality is limited by persistent rates of iatrogenic injury, commonly cited at $1 \%-5 \%$, as well as increased timing of 

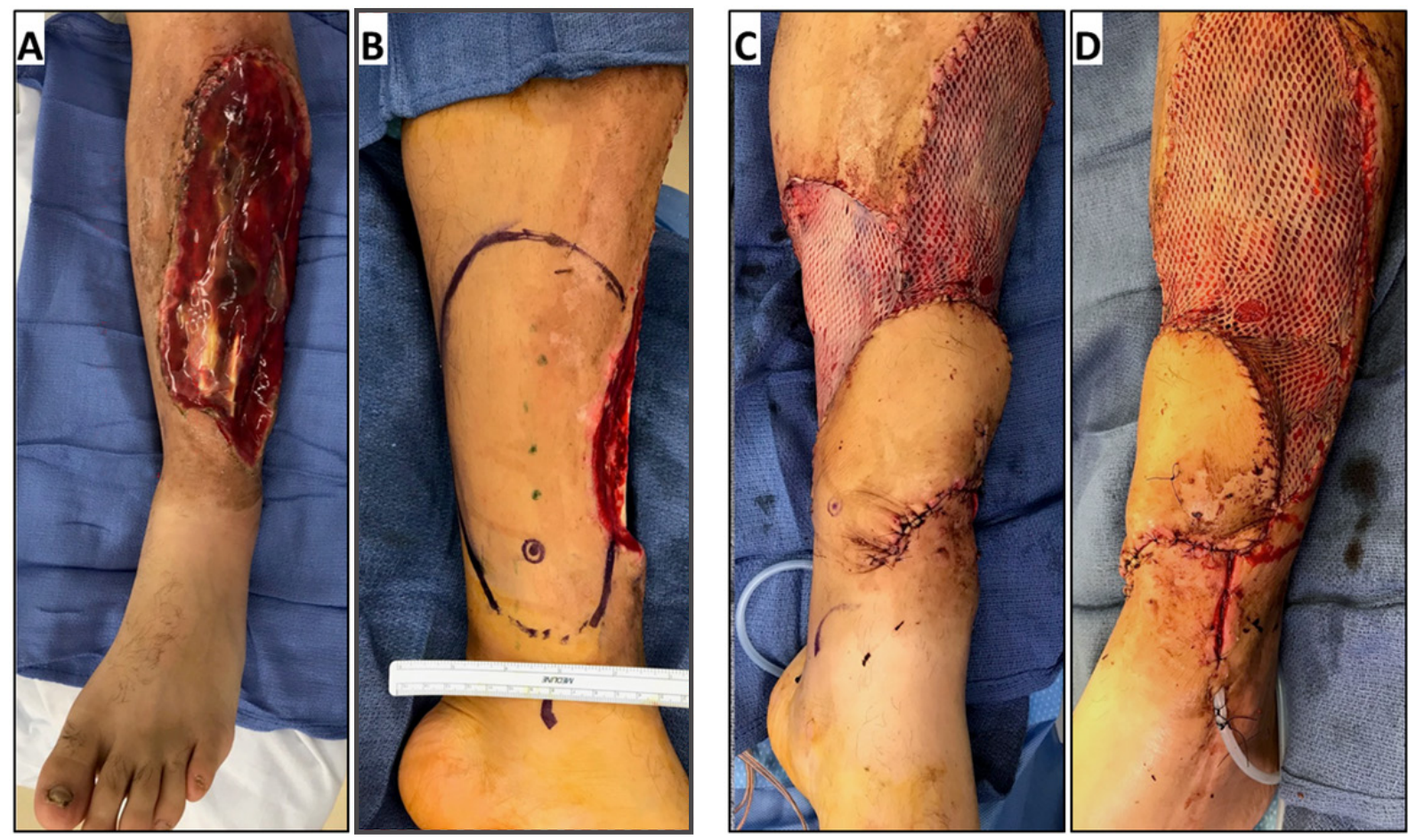

Figure 2. A: adult male following degloving injury to left lower extremity; B: preoperative marking for posterior tibial artery perforator propeller flap; C: immediate postoperative result, medial view; D: immediate postoperative result, lateral view

performance and cost to the hospital system ${ }^{[53,54]}$. Since its introduction in clinical practice in the early 1990s, computed tomographic angiography (CTA) has become the de-facto diagnostic modality of choice to assess vascular injury in the setting of lower-extremity trauma ${ }^{[55]}$. Due to a more favorable side-effect profile, as well as imaging resolution comparable to that of angiography, CTA has begun to replace arteriography as the preferred diagnostic modality to evaluate vascular injury ${ }^{[56,57]}$. Despite the obvious advantage of predisposing patient's to less ionizing radiation and the avoidance of complications such as pseudoaneurysm, vessel thrombosis, and vessel injury, the routine use of CTA has long been continuously debated but has gained routine acceptance in clinical practice ${ }^{[58]}$. While CT imaging may demonstrate vascular injury, and patency of residual vessels, this modality does little to evaluate flow in potential donor vessels to sustain microvascular reconstruction in the setting of collateral flow. Furthermore, the sensitivity of CTA is limited in the identification of vasospasm and local injury ${ }^{[59]}$. For these reasons, many institutions continue to rely on arteriography for preoperative imaging and planning. In individuals whose renal function preclude administration of iodinated dyes, carbon dioxide angiography remains a viable and underutilized imaging modality ${ }^{[6,61]}$. Compared with iodinated contrast, $\mathrm{CO}_{2}$ angiography decreases the incidence of acute kidney injury from $11.1 \%$ to $4.7 \%$. As such, $\mathrm{CO}_{2}$ angiography may provide valuable diagnostic data in populations unable to receive large contrast loads secondary to compromised renal function or adverse reactions to iodinated contrast.

When microvascular reconstruction is required, recipient vessel selection outside the zone of injury is of paramount importance, made more so by the limitations conferred by the associated injury. Some institutions argue for the continued utility of obtaining formal arteriography, but primarily in the setting of chronic lower extremity wounds, as these studies may demonstrate previously unrecognized vascular pathology and allow for prompt endovascular intervention facilitating ultimate reconstruction ${ }^{[62]}$. Others argue that any diagnostic imaging in the setting of trauma is superfluous, as thorough clinical examination and intraoperative adaptation are sufficient to conduct soft-tissue reconstruction ${ }^{[63]}$. 

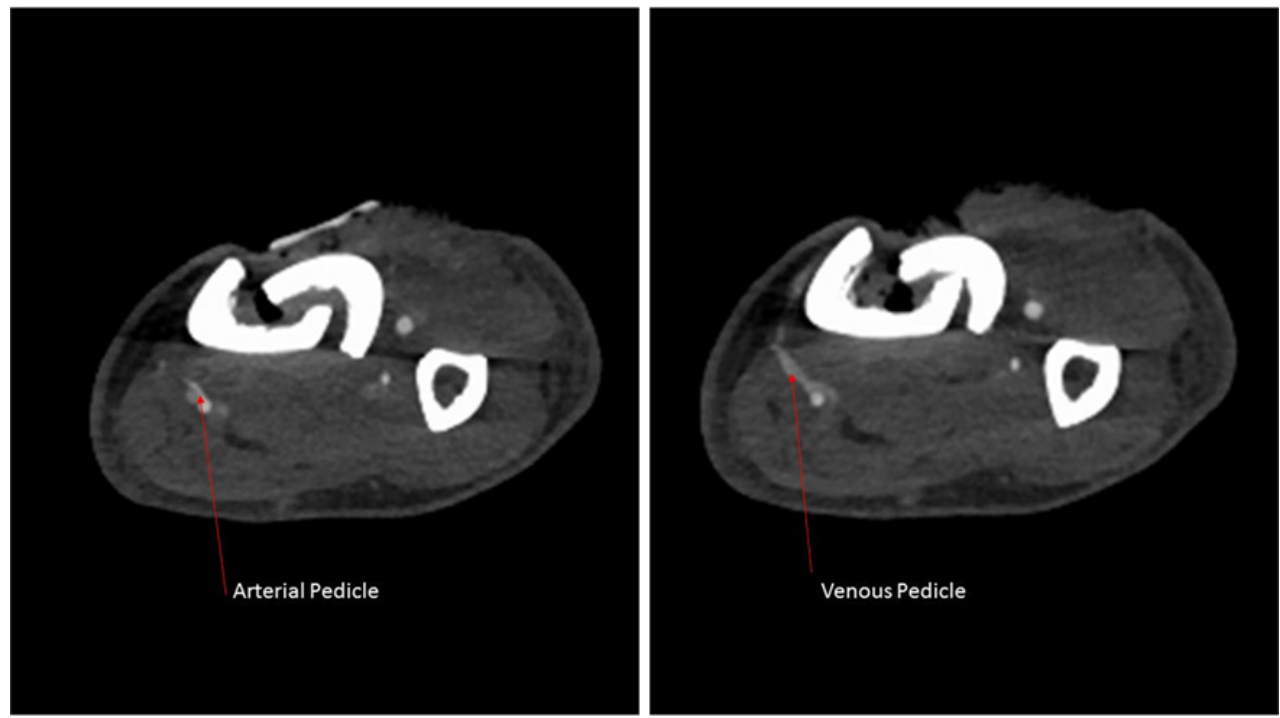

Figure 3. Computed tomographic angiography imaging of traumatized extremity with identification of potential recipient vessel prior to planned perforator flap for anterior tibial soft tissue

However, preoperative vessel imaging remains common practice in the traumatic setting. Similar to the evolution of imaging for the purposes of injury identification, vessel selection has evolved from the transition from angiography to CTA over the previous decade ${ }^{[64,65]}$. For the purposes of free-flap planning, Duymaz et al. ${ }^{[66]}$ were able to demonstrate the utility of obtaining lower extremity CTAs in correlating arterial injury with eventual flap loss, although no direct comparisons were made to preoperative angiography. As previously mentioned, routine use of CTA provides excellent assessment of lowerextremity anatomy without the associated co-morbidities of formal angiography [Figure 3].

Development of ancillary imaging modalities to assess perforator vessel for preoperative planning continues to evolve. Recent work by Feng et al. ${ }^{[6]]}$ suggests the use of color doppler ultrasound demonstrates greater fidelity of identifying and localizing dominant perforators of lower extremity flap when compared to CTA in a head-to-head comparison. The use of Indocyanine green (ICG) has also emerged as an adjunctive imaging modality to assess the microvasculature of perforator and local tissue flaps in microsurgical reconstruction. ICG is a cyanine dye with near-infrared spectral absorbance that binds circulating plasma proteins. As such, ICG in concert with near infrared imaging has been used across multiple medical disciplines for the purposes of vascular and lymph perfusion imaging. In the field of plastic surgery, ICG has been used with increasing frequency for the purposes of local, perforator, and freeflap perfusion distribution. Most published studies to date use ICG to assess viability of skin flaps of the trunk, head, and neck ${ }^{[68-70]}$. The technology was recently demonstrated, albeit in a limited series of 23 patients, to significantly improve complication rates of tissue necrosis and deep-space infection in patients with Gustilo Type IIIB when used as an adjunct to guide initial debridement ${ }^{[7]}$. While its use has yet to be routinely adopted, ICG has proven a reliable adjunct available to clinicians to assess tissue perfusion in the operating room.

\section{CONCLUSION}

Advances in microsurgical techniques, the advent of negative pressure wound technology in temporizing wound care, and improvements in preoperative imaging have facilitated changing treatment practices in the reconstruction of traumatic lower extremity injuries over the previous two decades. Despite persistent challenges, as evidenced by high rates of postoperative infection, flap loss, and poor functional recovery, 
reconstruction has become increasingly available for injuries previously thought to be unsalvageable. The pre-existing dogma advocating for immediate soft-tissue reconstruction within a 72 -h window has since been liberalized in the setting of improved wound-care, the widespread use of negative pressure wound therapy, and the advent of damage-control orthopedic surgery, allowing reconstruction of increasingly complex injuries in severely sick patients. The improved understanding of perfosomes and refinement of microsurgical technique have facilitated the paradigm of the reconstructive elevator to more closely approximate pre-morbid anatomy and function. The use of ancillary imaging including CTA, angiography, and doppler ultrasound has refined the identification and characterization of recipient vessels for freetissue transfers. As technological advances continue to augment preoperative assessment, routine wound care, and intraoperative planning, reconstruction will continue to more closely approximate pre-injury functionality, improving patient outcomes and satisfaction.

\section{DECLARATIONS}

\section{Authors' contributions}

Share conceptualization and authorship of this review: Zhang AY, Cholok D, Lee GK

Made substantial contributions in editing the manuscript: Lee GK

\section{Availability of data and materials}

Not applicable.

\section{Financial support and sponsorship}

None.

\section{Conflicts of interest}

All authors declared that there are no conflicts of interest.

\section{Ethical approval and consent to participate}

Not applicable.

\section{Consent for publication}

Not applicable.

\section{Copyright}

(c) The Author(s) 2019.

\section{REFERENCES}

1. 2012 National Trauma Data Bank Annual Report (2012:146;table 29 page 65). Available from: https://www.facs.org/-/media/files/ quality-programs/trauma/ntdb/ntdb-annual-report-2012.ashx [Last accessed on 13 Dec 2019].

2. Bosse MJ, MacKenzie EJ, Kellam JF, Burgess AR, Webb LX, et al. An analysis of outcomes of reconstruction or amputation after legthreatening injuries. N Engl J Med 2002;347:1924-31.

3. MacKenzie EJ, Bosse MJ, Kellam JF, Pollak AN, Webb LX, et al. Early predictors of long-term work disability after major limb trauma. J Trauma 2006;61:688-94.

4. Higgins TF, Klatt JB, Beals TC. Lower Extremity Assessment Project (LEAP) - the best available evidence on limb-threatening lower extremity trauma. Orthop Clin North Am 2010;41:233-9.

5. Baechler MF, Groth AT, Nesti LJ, Martin BD. Soft tissue management of war wounds to the foot and ankle. Foot Ankle Clin 2010;15:113-38.

6. Momoh AO, Kumaran S, Lyons D, Venkatramani H, Ramkumar S, et al. An argument for salvage in severe lower extremity trauma with posterior tibial nerve injury: the ganga hospital experience. Plast Reconstr Surg 2015;136:1337-52.

7. Helfet DL, Howey T, Sanders R, Johansen K. Limb salvage versus amputation. Preliminary results of the Mangled Extremity Severity Score. Clin Orthop Relat Res 1990;80-6.

8. Howe HR, Poole GV, Hansen KJ, Clark T, Plonk GW, et al. Salvage of lower extremities following combined orthopedic and vascular 
trauma. A predictive salvage index. Am Surg 1987;53:205-8.

9. Russell WL, Sailors DM, Whittle TB, Fisher DF, Burns RP. Limb salvage versus traumatic amputation. A decision based on a sevenpart predictive index. Ann Surg 1991;213:473-80; discussion 480-1.

10. McNamara MG, Heckman JD, Corley FG. Severe open fractures of the lower extremity: a retrospective evaluation of the Mangled Extremity Severity Score (MESS). J Orthop Trauma 1994;8:81-7.

11. Bosse MJ, MacKenzie EJ, Kellam JF, Burgess AR, Webb LX, et al. A prospective evaluation of the clinical utility of the lowerextremity injury-severity scores. J Bone Joint Surg Am 2001;83:3-14.

12. Gustilo RB, Anderson JT. Prevention of infection in the treatment of one thousand and twenty-five open fractures of long bones: retrospective and prospective analyses. J Bone Joint Surg Am 1976;58:453-8.

13. Gustilo RB, Mendoza RM, Williams DN. Problems in the management of type III (severe) open fractures: a new classification of type III open fractures. J Trauma 1984;24:742-6.

14. Brumback RJ, Jones AL. Interobserver agreement in the classification of open fractures of the tibia. The results of a survey of two hundred and forty-five orthopaedic surgeons. J Bone Joint Surg Am 1994;76:1162-6.

15. MacKenzie EJ, Bosse MJ, Kellam JF, Burgess AR, Webb LX, et al. Factors influencing the decision to amputate or reconstruct after high-energy lower extremity trauma. J Trauma 2002;52:641-9.

16. Godina M. Early microsurgical reconstruction of complex trauma of the extremities. Plast Reconstr Surg 1986;78:285-92.

17. Byrd HS, Spicer TE, Cierney G. Management of open tibial fractures. Plast Reconstr Surg 1985;76:719-30.

18. Qiu E, Kurlander DE, Ghaznavi AM. Godina revisited: a systematic review of traumatic lower extremity wound reconstruction timing. J Plast Surg Hand Surg 2018;52:259-64.

19. Francel TJ, Vander Kolk CA, Hoopes JE, Manson PN, Yaremchuk MJ. Microvascular soft-tissue transplantation for reconstruction of acute open tibial fractures: timing of coverage and long-term functional results. Plast Reconstr Surg 1992;89:478-87; discussion 488-9.

20. Karanas YL, Nigriny J, Chang J. The timing of microsurgical reconstruction in lower extremity trauma. Microsurgery 2008;28:632-4.

21. Lee ZH, Stranix JT, Rifkin WJ, Daar DA, Anzai L, et al. Timing of microsurgical reconstruction in lower extremity trauma: an update of the godina paradigm. Plast Reconstr Surg 2019;144:759-67.

22. Steiert AE, Gohritz A, Schreiber TC, Krettek C, Vogt PM. Delayed flap coverage of open extremity fractures after previous vacuumassisted closure (VAC) therapy - worse or worth? J Plast Reconstr Aesthetic Surg 2009;62:675-83.

23. Liu DSH, Sofiadellis F, Ashton M, MacGill K, Webb A. Early soft tissue coverage and negative pressure wound therapy optimises patient outcomes in lower limb trauma. Injury 2012;43:772-8.

24. Hill JB, Vogel JE, Sexton KW, Guillamondegui OD, Corral GAD, et al. Re-evaluating the paradigm of early free flap coverage in lower extremity trauma. Microsurgery 2013;33:9-13.

25. Raju A, Ooi A, Ong YS, Tan BK. Traumatic lower limb injury and microsurgical free flap reconstruction with the use of negative pressure wound therapy: is timing crucial? J Reconstr Microsurg 2014;30:427-30.

26. Sheckter CC, Pridgen B, Li A, Curtin C, Momeni A. Regional variation and trends in the timing of lower extremity reconstruction: a 10-year review of the nationwide inpatient sample. Plast Reconstr Surg 2018;142:1337-47.

27. Pollak AN, Ficke JR, Extremity War Injuries III Session Moderators. Extremity war injuries: challenges in definitive reconstruction. J Am Acad Orthop Surg 2008;16:628-34.

28. Rinker B, Amspacher JC, Wilson PC, Vasconez HC. Subatmospheric pressure dressing as a bridge to free tissue transfer in the treatment of open tibia fractures. Plast Reconstr Surg 2008;121:1664-73.

29. Argenta LC, Morykwas MJ. Vacuum-assisted closure: a new method for wound control and treatment: clinical experience. Ann Plast Surg 1997;38:563-76; discussion 577 .

30. Webb LX. New techniques in wound management: vacuum-assisted wound closure. J Am Acad Orthop Surg 2002;10:303-11.

31. Patterson CW, Stalder MW, Richardson W, Steele T, Wise MW, et al. Timing of free flaps for traumatic wounds of the lower extremity: have advances in perioperative care changed the treatment algorithm? J Reconstr Microsurg 2019;35:616-21.

32. Shammas RL, Mundy LR, Truong T, Weber JM, Grier AJ, et al. Identifying predictors of time to soft-tissue reconstruction following open tibia fractures. Plast Reconstr Surg 2018;142:1620-8.

33. Gubin A, Borzunov D, Malkova T. Ilizarov method for bone lengthening and defect management review of contemporary literature. Bull Hosp Jt Dis (2013) 2016;74:145-54.

34. Green SA. Skeletal defects. A comparison of bone grafting and bone transport for segmental skeletal defects. Clin Orthop 1994;111-7.

35. Attias N, Lindsey RW. Case reports: management of large segmental tibial defects using a cylindrical mesh cage. Clin Orthop 2006;450:259-66.

36. Masquelet A, Kanakaris NK, Obert L, Stafford P, Giannoudis PV. Bone repair using the masquelet technique. J Bone Joint Surg Am 2019;101:1024-36.

37. Masquelet AC, Fitoussi F, Begue T, Muller GP. Reconstruction of the long bones by the induced membrane and spongy autograft. Ann Chir Plast Esthet 2000;45:346-53.

38. Pelissier P, Bollecker V, Martin D, Baudet J. Foot reconstruction with the "bi-Masquelet" procedure. Ann Chir Plast Esthet 2002;47:304-7.

39. Giannoudis PV, Harwood PJ, Tosounidis T, Kanakaris NK. Restoration of long bone defects treated with the induced membrane technique: protocol and outcomes. Injury 2016;47 Suppl 6:S53-61.

40. Karger C, Kishi T, Schneider L, Fitoussi F, Masquelet AC, French Society of Orthopaedic Surgery and Traumatology (SoFCOT). Treatment of posttraumatic bone defects by the induced membrane technique. Orthop Traumatol Surg Res 2012;98:97-102. 
41. Gottlieb LJ, Krieger LM. From the reconstructive ladder to the reconstructive elevator. Plast Reconstr Surg 1994;93:1503-4.

42. Cho EH, Shammas RL, Carney MJ, Weissler JM, Bauder AR, et al. Muscle versus fasciocutaneous free flaps in lower extremity traumatic reconstruction: a multicenter outcomes analysis. Plast Reconstr Surg 2018;141:191-9.

43. Hong JP, Shin HW, Kim JJ, Wei FC, Chung YK. The use of anterolateral thigh perforator flaps in chronic osteomyelitis of the lower extremity. Plast Reconstr Surg 2005;115:142-7.

44. Xiong L, Gazyakan E, Kremer T, Hernekamp FJ, Harhaus L, et al. Free flaps for reconstruction of soft tissue defects in lower extremity: a meta-analysis on microsurgical outcome and safety. Microsurgery 2016;36:511-24.

45. Veith J, Donato D, Holoyda K, Simpson A, Agarwal J. Variables associated with 30-day postoperative complications in lower extremity free flap reconstruction identified in the ACS-NSQIP database. Microsurgery 2019;39:621-8.

46. Stranix JT, Lee ZH, Jacoby A, Anzai L, Avraham T, et al. Not all gustilo type iiib fractures are created equal: arterial injury impacts limb salvage outcomes. Plast Reconstr Surg 2017;140:1033-41.

47. Fischer JP, Wink JD, Nelson JA, Cleveland E, Grover R, et al. A retrospective review of outcomes and flap selection in free tissue transfers for complex lower extremity reconstruction. J Reconstr Microsurg 2013;29:407-16.

48. Cho EH, Garcia RM, Pien I, Kuchibhatla M, Levinson H, et al. Vascular considerations in foot and ankle free tissue transfer: analysis of 231 free flaps. Microsurgery 2016;36:276-83.

49. Nelson JA, Fischer JP, Brazio PS, Kovach SJ, Rosson GD, et al. A review of propeller flaps for distal lower extremity soft tissue reconstruction: is flap loss too high? Microsurgery 2013;33:578-86.

50. Saint-Cyr M, Wong C, Schaverien M, Mojallal A, Rohrich RJ. The perforasome theory: vascular anatomy and clinical implications. Plast Reconstr Surg 2009;124:1529-44.

51. Baumeister SP, Spierer R, Erdmann D, Sweis R, Levin LS, et al. A realistic complication analysis of 70 sural artery flaps in a multimorbid patient group. Plast Reconstr Surg 2003;112:129-40; discussion 141-2.

52. Parrett BM, Pribaz JJ, Matros E, Przylecki W, Sampson CE, et al. Risk analysis for the reverse sural fasciocutaneous flap in distal leg reconstruction. Plast Reconstr Surg 2009;123:1499-504.

53. Hessel SJ, Adams DF, Abrams HL. Complications of angiography. Radiology 1981;138:273-81.

54. Waugh JR, Sacharias N. Arteriographic complications in the DSA era. Radiology 1992;182:243-6.

55. Johansen K, Lynch K, Paun M, Copass M. Non-invasive vascular tests reliably exclude occult arterial trauma in injured extremities. J Trauma 1991;31:515-9; discussion 519-22.

56. Rubin GD, Schmidt AJ, Logan LJ, Sofilos MC. Multi-detector row CT angiography of lower extremity arterial inflow and runoff: initial experience. Radiology 2001;221:146-58.

57. Seamon MJ, Smoger D, Torres DM, Pathak AS, Gaughan JP, et al. A prospective validation of a current practice: the detection of extremity vascular injury with CT angiography. J Trauma 2009;67:238-43; discussion 243-4.

58. Klein MB, Karanas YL, Chow LC, Rubin GD, Chang J. Early experience with computed tomographic angiography in microsurgical reconstruction. Plast Reconstr Surg 2003;112:498-503.

59. Soto JA, Múnera F, Morales C, Lopera JE, Holguín D, et al. Focal arterial injuries of the proximal extremities: helical CT arteriography as the initial method of diagnosis. Radiology 2001;218:188-94.

60. Stegemann E, Tegtmeier C, Bimpong-Buta NY, Sansone R, Uhlenbruch M, et al. Carbondioxide-aided angiography decreases contrast volume and preserves kidney function in peripheral vascular interventions. Angiology 2016;67:875-81.

61. Sharafuddin MJ, Marjan AE. Current status of carbon dioxide angiography. J Vasc Surg 2017;66:618-37.

62. Janhofer DE, Lakhiani C, Kim PJ, Akbari C, Naz I, et al. The utility of preoperative arteriography for free flap planning in patients with chronic lower extremity wounds. Plast Reconstr Surg 2019;143:604-13.

63. Lutz BS, Ng SH, Cabailo R, Lin CH, Wei FC. Value of routine angiography before traumatic lower-limb reconstruction with microvascular free tissue transplantation. J Trauma 1998;44:682-6.

64. May JW, Athanasoulis CA, Donelan MB. Preoperative magnification angiography of donor and recipient sites for clinical free transfer of flaps or digits. Plast Reconstr Surg 1979;64:483-90.

65. Chen HC, Chuang CC, Chen S, Hsu WM, Wei FC. Selection of recipient vessels for free flaps to the distal leg and foot following trauma. Microsurgery 1994;15:358-63.

66. Duymaz A, Karabekmez FE, Vrtiska TJ, Mardini S, Moran SL. Free tissue transfer for lower extremity reconstruction: a study of the role of computed angiography in the planning of free tissue transfer in the posttraumatic setting. Plast Reconstr Surg 2009;124:523-9.

67. Feng S, Min P, Grassetti L, Lazzeri D, Sadigh P, et al. A prospective head-to-head comparison of color doppler ultrasound and computed tomographic angiography in the preoperative planning of lower extremity perforator flaps. Plast Reconstr Surg 2016;137:335-47.

68. Holm C, Mayr M, Höfter E, Becker A, Pfeiffer UJ, et al. Intraoperative evaluation of skin-flap viability using laser-induced fluorescence of indocyanine green. Br J Plast Surg 2002;55:635-44.

69. Woodard CR, Most SP. Intraoperative angiography using laser-assisted indocyanine green imaging to map perfusion of forehead flaps. Arch Facial Plast Surg 2012;14:263-9.

70. Monahan J, Hwang BH, Kennedy JM, Chen W, Nguyen GK, et al. Determination of a perfusion threshold in experimental perforator flap surgery using indocyanine green angiography. Ann Plast Surg 2014;73:602-6.

71. Koshimune S, Shinaoka A, Ota T, Onoda S, Kimata Y. Laser-assisted indocyanine green angiography aids in the reconstruction of gustilo grade iiib open lower-limb fractures. J Reconstr Microsurg 2017;33:143-50. 